\title{
The Cracks
}

\section{Teri Louise Kelly}

There's only one way out of here, the astronaut knows gravity is a sleeper hold.

I search the small print for the words 'miracles guaranteed', listen to the screams from the cracks opening underfoot two rats on the crossbeam squat $\&$ smile through nicotine aneurysms admonishing me via inter-species communiqué the army of pontification stands stonily silent unwilling to vacate wood panelled halls I am a numeric statistic in the primordial census the roaches $\&$ the grasshoppers are pre-cooking strategies on gas mark twelve reading Sylvia Plath the recipe of extermination and reclamation simmer, stir, blend, pat into tablet form when frigidly cold brand new zephyrs bring omens \& long lost psalms on an oaken pew the old man sits chin on clenched fist Tokyo is no longer an option, Berlin long since fallen, London burned, he heard . . . the barkeep has a sermon some warped version of apocalypse imminent topped with a twist of lime! In Mexico no one passes to the other side, wordsmiths thrive on succulent delights, the insects sit \& listen to the cracks yawning. 